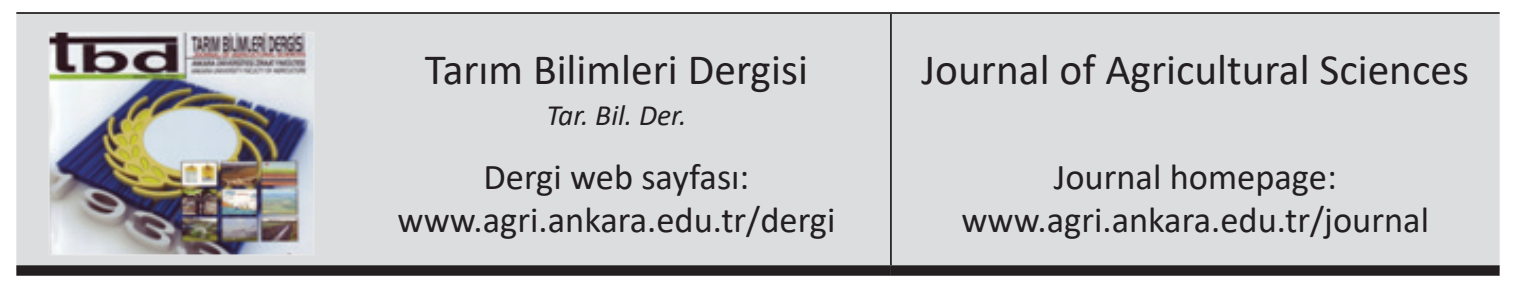

\title{
Effects of Alginate Based Coatings with Pomegranate Peel Extract on the Microbial Quality of Mackerel Fillets
}

\author{
Fatma ÖZTÜRK ${ }^{\mathrm{a}}$, Hatice GÜNDÜZ ${ }^{\mathrm{a}}$, Göknur SÜRENGIL ${ }^{\mathrm{a}}$ \\ azmir Katip Celebi University, Faculty of Fisheries, Izmir, TURKEY
}

\author{
ARTICLE INFO \\ Research Article \\ DOI: 10.15832 /ankutbd.490936 \\ Corresponding Author: Fatma ÖZTÜRK, E-mail: fatma.ozturk@ikc.edu.tr, Tel: +90 (232) 3293535 / 4215 \\ Received: 02 March 2017, Received in Revised Form: 29 December 2017, Accepted: 03 January 2018
}

\begin{abstract}
In this study, antibacterial effects of the pomegranate peel extract against food pathogens were investigated. Different concentrations of pomegranate peel extract $(2.5,5,7.5$ and 10\%), which showed the highest antibacterial effect in vitro experiments were added to the alginate film. Mackerel fillets coated with the film solution prepared in this way were stored at $4 \pm 1{ }^{\circ} \mathrm{C}$ for 13 days. L. monocytogenes, total aerobic mesophilic bacteria, total aerobic psychrophilic bacteria, total yeast-mould and enterobacteriaceae counts were determined on $0,3^{\text {rd }}, 8^{\text {th }}$, and $13^{\text {th }}$ day of storage period.

At the end of the study; it was determined that the pomegranate extract was effective and the inhibition effect was also increased based on the increase in extract concentration. Different concentrations of pomegranate peel extract showed antibacterial effect against L. monocytogenes, E. coli $\mathrm{O} 157: \mathrm{H} 7$, and $S$. aureus $(\mathrm{P}<0.05)$. As a result of 13 days storage of mackerel fillets coated with alginate enriched with 2.5, 5, 7.5 and $10 \% \mathrm{PPE}$ at $4{ }^{\circ} \mathrm{C}$, the number of L. monocytogenes significantly decreased $(\mathrm{P}<0.05)$. During the storage period total aerobic mesophilic bacteria and enterobacteriaceae number were found to be significantly lower in the experimental groups used pomegranate peel extract in comparison with the control group. As a result, it was determined that pomegranate peel extract has a potential to be used as a natural preservative in seafood products.
\end{abstract}

Keywords: Pomegranate peel extract; Antimicrobial film; L. monocytogenes

(C) Ankara Üniversitesi Ziraat Fakültesi

\section{Introduction}

The Listeria monocytogenes is a gram-positive, asporous, facultative anaerobic bacterium that causes listeriosis from foodborne diseases. It has been reported that most of the listeriosis outbreaks occur through ready-to-eat foods such as dairy products, salads, seafood, processed meats and poultry (Chan \& Wiedmann 2009). Synthetic antimicrobial agents are widely used to prevent the development of pathogenic bacteria such as
L. monocytogenes in foods, but concerns about the safety of these chemicals are increasing day by day (Owen \& Palombo 2007). For this reason, the fruits, vegetables, spices, plants or their extracts that are enrich in terms of phenolic compounds are used to avoid the development of pathogenic or spoilage bacteria and to prolong the shelf life of food (Rawdkuen et al 2012).

Today, the use of agricultural food industry's by-products or wastes has become one of the 
environmental and economic priorities. It is known that the roots, peels and leaves of many fruits and vegetables have therapeutic properties (Balasundram et al 2006). It was revealed that processing wastes rich in bioactive compounds can be an alternative of synthetic chemical additives because of their antioxidant and antimicrobial features in many studies (Negi \& Jayaprakasha 2003; Kanatt et al 2010).

Pomegranate (Punica granatum L.) is a fruit commonly produced in our country, and consumed after being processed into by-products such as both fresh and pomegranate syrup or pomegranate vinegar. PP accounts for almost $50 \%$ of the total fruit weight, concurrently it contains elagic acid and its derivatives and bioactive compounds such as alegrate and hexahydroxydiphenic acid (Gullon et al 2016). Pomegranate extract is very rich in terms of phytocompounds such as phenol, tannin and flavonoids (Jurenka 2008). Because of the compounds contained in this fruit, it was stated to be able to use as antioxidants and antimicrobials both in the food industry and in the medicine (Al-Zoreky 2009).

Edible films are thin-bedded, eatable with food, and non-synthetic materials, derived from natural sources that are used to protect food and extend shelf-life (Dursun \& Erkan 2009). Antioxidants, antimicrobials, colorants and spices can be added to the edible films to able to achieve functional properties to the products (Emiroğlu et al 2010).

The purpose of this study is to determine the antibacterial effect of the alginate based coatings with pomegranate peel exctracts on the mackerel fillets in refrigerated storage.

\section{Material and Methods}

\subsection{Material}

The mackerel fish (Scomber scombrus) used in the study was procured from Izmir fish market. Pomegranate whose antibacterial effects were determined were procured from local markets.
The L. monocytogenes, Escherichia coli, Escherichia coli O157:H7, Bacillus cereus, Salmonella enteritis and Staphylococcus aureus were procured from İzmir Katip Celebi University Aquaculture Faculty culture collection.

\subsection{Method}

\subsubsection{Preparation of the extract}

The pomegranate peel were dried in drying oven at $50{ }^{\circ} \mathrm{C}$. These dried samples were shredded to small pieces by a wiring blender. $20 \mathrm{~g}$ of dried samples were extracted with $100 \mathrm{~mL}$ solvent ( $80 \%$ ethanol). The mixture was kept in a shaking water bath for 6 hours at $50{ }^{\circ} \mathrm{C}$ and was filtered. This process was repeated 4 times. This latter was evaporated in a rotary evaporator, finally freezed and lyophilised (Feresin et al 2000; Keyrouz et al 2011).

\subsubsection{Preparation of bacterial inoculums}

The stock cultures of L. monocytogenes, E. coli, E. coli O157:H7, B. cereus, S. enteritis and $S$. aureus that are in liquid form were stored at $-20 \pm 2{ }^{\circ} \mathrm{C}$ on glycerol containing $\left(20 \% ; \mathrm{v} \mathrm{v}^{-1}\right)$. For the experiments, $100 \mu \mathrm{L}$ of stock cultures were transferred to $10 \mathrm{~mL}$ MHB medium, and the bacteria were activated by incubation at $30^{\circ} \mathrm{C}$ for 24 hours.

\subsubsection{Disk diffusion method (Kirby-Bauer method)}

The disk diffusion method was used to determine the antibacterial activities of pomegranate peel extracts (Melendez \& Capriles 2006). $25 \mu \mathrm{L}$ (0.25, $0.50,1,1.5,2.5,5,7.5$ and $10 \%$ concentrations) of pomegranate peel extracts were soaked into sterile empty discs placed in petri dishes in which planting was made. The petri dishes in which planting were made were left to the incubation process at $30^{\circ} \mathrm{C}$ for 24 hours. The activation process was repeated twice.

\subsubsection{Preparation of film solution and application to mackerel fillets}

Sodium alginate (Kimbiotek) and $\mathrm{CaCl}_{2}$ (Merck) were used to prepare the film solution. $30 \mathrm{~g}$ of sodium alginate was mixed with $1000 \mathrm{~mL}$ of distilled water and adjusted to $80{ }^{\circ} \mathrm{C}$. The mixture kept in 
a magnetic stirrer. After having been cooled until $50{ }^{\circ} \mathrm{C}$, the pomegranate extracts at concentrations of $2.5,5,7.5$ and $10 \%$ were added into it. $50 \mathrm{~g}$ of mackerel fillets were inoculated by spreading L. monocytogenes to a final concentration of $10^{4} \mathrm{CFU}$ $\mathrm{g}^{-1}$. Then the fillets were immersed in $3 \%$ alginate solution containing $2.5,5,7.5,10 \% \mathrm{PPE}$ and left for 1 minute. The samples coated with alginate film without PPE were used as control. This process has been repeated twice. Fillets coated with alginate were immersed in the $2 \% \mathrm{CaCl}_{2}$ solution and kept (3 minute) for solidification (Song et al 2011). The fillets prepared like this were packaged and stored in the refrigerator $\left(4 \pm 1{ }^{\circ} \mathrm{C}\right)$ for 13 days.

\subsubsection{Determination of the number of $L$. monocytogenes in mackerel fillets coated with alginate film}

The number of L. monocytogenes were determined on $0,3^{\text {rd }}, 8^{\text {th }}$, and $13^{\text {th }}$ day of storage period. For this, the mackerel filet was transferred to the Maximum Recovery Diluent (MRD) solution and homogenized. It was diluted up to the dilutions of $10^{6}$ from homogenate taking into account the $10^{-1}$ dilution rate, and planting according to the Most Probable Number (MPN) method. For this purpose, $1 \mathrm{~mL}$ of the appropriate dilutions was transferred to a $10 \mathrm{~mL}$ Fraser broth medium, and incubated at 37 ${ }^{\circ} \mathrm{C}$ for 24 hours. The number of $L$. monocytogenes was determined by being evaluated the tubes in which the growth was occurred after the incubation (Halkman 2005).

\subsubsection{The microbiological analysis on mackerel fillets coated with alginate film}

The number of total aerobic mesophilic bacteria, total aerobic psychrophilic bacteria, total yeastmould and enterobacteriaceae were performed on 0 , $3^{\text {rd }}, 8^{\text {th }}$, and $13^{\text {th }}$ day of storage period.

The mackerel filet was transferred to the Maximum Recovery Diluent (MRD) solution and homogenized. $0.1 \mathrm{~mL}$ was taken from the appropriate dilutions and planted in petri dishes containing nutrient with spreading method. PCA was used for TAMB and incubated for 24-48 hours at $30{ }^{\circ} \mathrm{C}$; PCA was used for TAPB and incubated for 10 days at $6.5^{\circ} \mathrm{C}$; PDA was used for TYM counts and incubated for $4-5$ days at $30^{\circ} \mathrm{C}$; and VRBA was used for enterobacteriaceae count and incubated for 24 hours at $37^{\circ} \mathrm{C}$. Bacterial counts were determined by counting the colonies growing on the medium at the end of incubation (Harrigan 1998).

\subsubsection{Statistical analysis}

The obtained data were analyzed using ANOVA (analysis of variance).The results were evaluated by Duncan Multiple Comparison Test. The SPSS statistical package program was used to test whether there is any difference between the application groups (IBM SPSS 2012).

\section{Results and Discussion}

\subsection{Antibacterial activities of extracts}

Antibacterial properties of extracts obtained from pomegranate peel were investigated in this study. The inhibition zone diameters of the extracts against the tested microorganisms were given in Figure 1. Different concentrations of PPE have antibacterial effect against L. monocytogenes, E. coli O157:H7 and $S$. aureus $(\mathrm{P}<0.05)$. Similar results have been identified by different investigators. Al-Zoreky (2009) reported that PPE could be used for the inactivation of L. monocytogenes, S. aureus, E. coli and Yersinia enterocolitica. Prashanth et al (2001) the highest inhibitory effect was obtained in $P$. vulgaris and B. subtilis. Ahmad \& Beg (2001) determined that extracts of pomegranate displayed antibacterial effect against $S$. aureus, E. coli and Shigella dysenteriae.

It was determined that the inhibition effect also increased based on increasing in PPE concentration. The highest inhibition zone was obtained from $10 \%$ PPE and the zone diameters for $S$. enteritis, B. cereus, E. coli O157:H7, E. coli, S. aureus and L. monocytogenes were determined as $18,22,24,17$, 16 and $23 \mathrm{~mm}$, respectively. Al-Zoreky (2009) found these zone diameters as 17, 16, 13 and $20 \mathrm{~mm}$ for Bacillus, E. coli, S. aureus and L. monocytogenes, respectively. In the study in which Dahham et al 


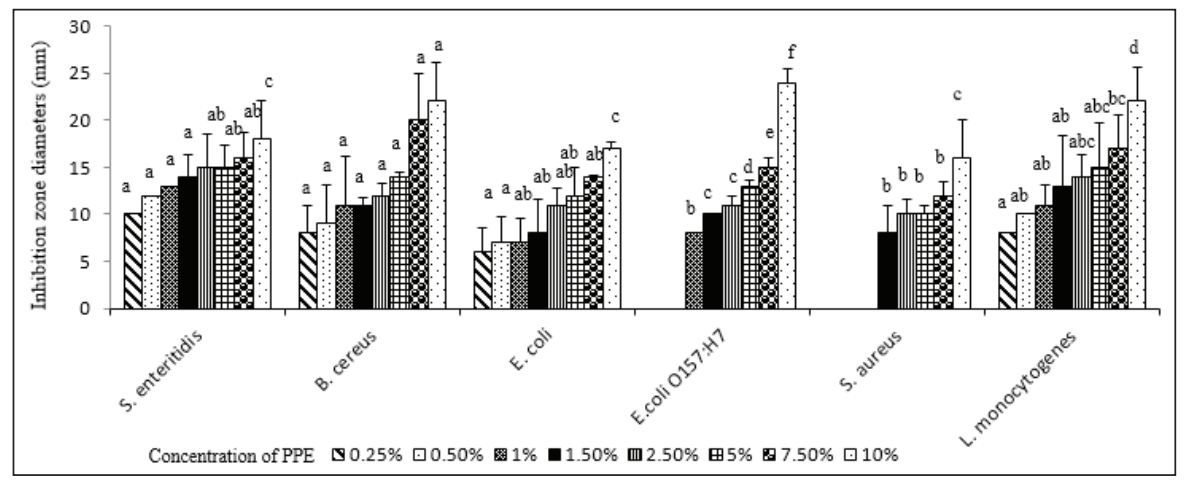

Figure 1- Antibacterial activity of PPE against bacterial species tested using disc diffusion assay

(2010) determined that the inhibition zone diameters obtained from pomegranate peel were in the length of $25 \mathrm{~mm}$ for B. cereus, $20 \mathrm{~mm}$ for E. coli and 25 $\mathrm{mm}$ for $S$. aureus. Whereas Melendez \& Capriles (2006) found these as $12 \mathrm{~mm}$ for E. coli and $22 \mathrm{~mm}$ for $S$. aureus. Mathabe et al (2006) reported that the extracts obtained from pomegranate are effective on S. aureus, E. coli, Salmonella typhi, Vibrio cholera, S. dysenteriae, S. sonnei, S. flexneri and $S$. boydii, and that they had the inhibition zones whose diameters were between 12 and $31 \mathrm{~mm}$.

According to the results obtained by Hayrapetyan et al (2012), L. monocytogenes, Bacillus subtilis, B. cereus, E. coli and S. aureus showed susceptible to PPE, respectively. According to the result that were obtained by them, S. aureus, B. cereus, E. coli and $B$. subtilis bacteria were found to be more sensitive to PE compared to L. monocytogenes. S. aureus were reported to show the highest sensitivity among the tested microorganisms. The results that we obtained are similar to those of other researchers, and it was determined that PPE can be used effectively against many food pathogens.

\subsection{Changes in L. monocytogenes number of mackerel fillets during refrigerated storage}

The number of L. monocytogenes detected during storage $(0,3,8$ and 13 . days) of mackerel fillets coated with alginate film containing PPE at $4{ }^{\circ} \mathrm{C}$ is given in Figure 2.

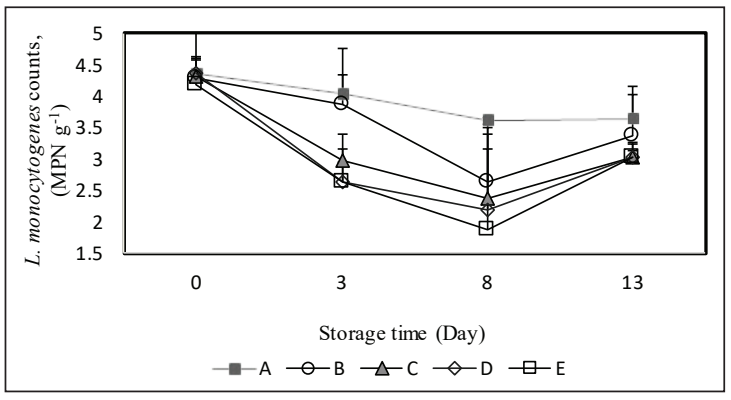

Figure 2- Changes in L. monocytogenes number of mackerel fillets during refrigerated storage (A, control group-without PPE; B, samples treated with 2.5\% PPE; C, samples treated with 5\% PPE; D, samples treated with $7.5 \%$ PPE; E, samples treated with $10 \%$ PPE)

The number of L. monocytogenes on mackerel fillets was significantly higher $(\mathrm{P}<0.05)$ for untreated samples than for treated samples. But the difference between PPE treated groups was not statistically significant $(P>0.05)$. At the beginning of storage, the number of bacteria that had been $10^{4} \mathrm{MPN} \mathrm{g}^{-1}$, was determined after 8 day storage as $4.3 \times 10^{3} \mathrm{MPN} \mathrm{g}^{-1}$ in the control group and $7.4 \times 10^{1} \mathrm{MPN} \mathrm{g}^{-1}$ in the samples treated with $10 \%$ PPE. At the end of 8 days of storage, the number of L. monocytogenes decreased significantly due to the increase in the extract concentration. The antibacterial effect of PPE was determined on many bacterial species in both 
in vitro and in vivo conditions. It was determined that the PPE prepared by Al-Zoreky (2009) using $80 \%$ methanol has an inhibitory effect against L. monocytogenes, S. aureus, Escherichia coli and Yersinia enterocolitica. The methanolic of PPE caused decreasing more than $1 \log$ in the number of L. monocytogenes of the fish stored at $4{ }^{\circ} \mathrm{C}$. At the last of the 46-day storage period and at $4{ }^{\circ} \mathrm{C}$, Hayrapetyan et al (2012) found that the number of $L$. monocytogenes of meat patties that of the controls and samples treated with $7.5 \%$ of were $4.1 \log \mathrm{CFU} \mathrm{g}{ }^{-1}, 9.2 \log \mathrm{CFU} \mathrm{g}{ }^{-1}$, respectively. $\mathrm{Wu}$ et al (2016), in an experiment conducted on the survival level of L. monocytogenes and $V$. parahaemolyticus in the cooked shrimp and raw tuna fish which PPE was applied, they found that the count of L. monocytogenes in the samples was $2 \log$ less than the control group.
3.3. Changes in the number of TAMB, TAPB and enterobacteriaceae in mackerel fillets during refrigerated storage

The change in the number of TAMB during 13 days of storage $(0,3,8$ and 13 . days) is given in Figure 3a. The count of TAMB was determined less in all groups with PPE than the control group. As the PPE concentration increased, the number of TAMB decreased significantly. At the end of 13 days of storage at $4{ }^{\circ} \mathrm{C}$ the lowest number of TAMB was detected in the experimental group to which was applied 10\% PPE $(\mathrm{P}<0.05)$.

The number of TAMB (means \pm standard errors) of the controls and of samples treated with 2.5 , $5,7.5$ and $10 \%$ PPE were $6.96 \pm 0.03,6.53 \pm 0.20$, $6.46 \pm 0.11,6.41 \pm 0.04$ and $6.18 \pm 0.02 \log \mathrm{CFU} \mathrm{g}{ }^{-1}$, respectively, at the last of the storage period.
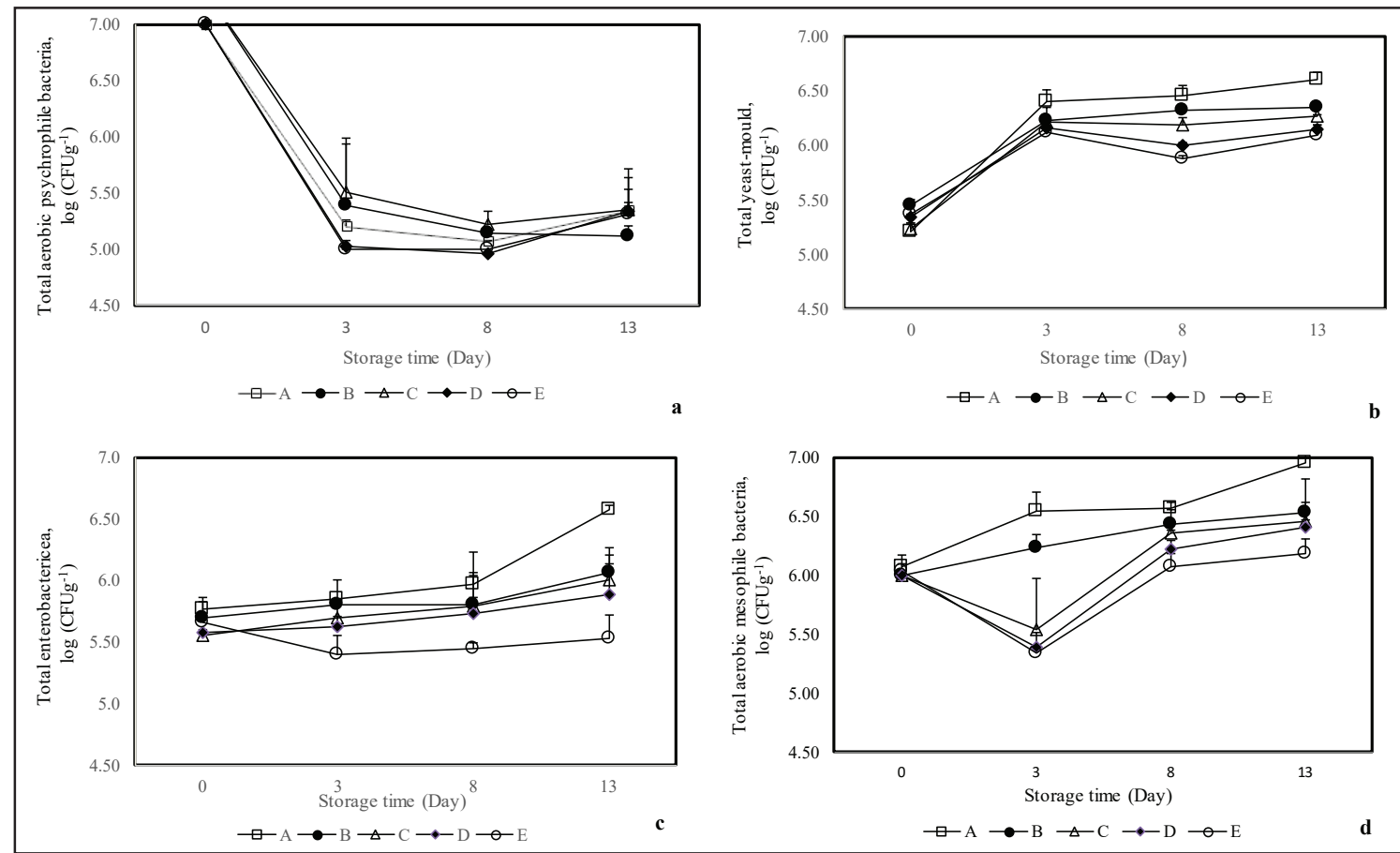

Figure 3- Changes in the number of TAMB (a), TAPB (b), enterobacteriaceae (c) and TYM (d) in mackerel fillets during refrigerated storage. (A, control group-without PPE; B, samples treated with 2.5\% PPE; C, samples treated with 5\% PPE; D, samples treated with 7.5\% PPE; E, samples treated with 10\% PPE) 
The change in the total number of TAPB is given in Figure $3 \mathrm{~b}$. At the end of storage (day 13), the number of TAPB of the controls and of samples treated with $2.5,5,7.5$ and $10 \%$ PPE were determined as $5.35 \pm 0.05,5.11 \pm 0.07,5.35 \pm 0.12$, $5.34 \pm 0.26$ and $5.31 \pm 0.23 \log \mathrm{CFU} \mathrm{g}{ }^{-1}$, respectively. The results indicated that there was no significant differences among the groups in terms of TAPB during the storage period $(\mathrm{P}>0.05)$.

The change in the TYM counts is given in Figure $3 \mathrm{c}$. On the $13^{\text {th }}$ day of storage, TYM counts of the controls and of samples treated with 2.5, 5, 7.5 and $10 \%$ PPE were determined as $6.60 \pm 0.05,6.34 \pm 0.02$, $6.27 \pm 0.01,6.15 \pm 0.05$ and $6.09 \pm 0.07 \log \mathrm{CFU} \mathrm{g}^{-1}$, respectively. Significant differences between TYM levels of control and other groups have not been observed $(\mathrm{P}>0.05)$.

The change in the number of enterobacteriaceae in the mackerel fillets stored at $+4{ }^{\circ} \mathrm{C}$ is given in Figure 3d. When compared with the control group, the number of enterobacteriaceae was determined to be lower in the groups to which samples treated with $10 \% \operatorname{PPE}(\mathrm{P}<0.05)$. At the end of storage, the number of enterobacteriaceae controls and of samples treated with 2.5, 5, 7.5 and $10 \%$ PPE were determined as $6.57 \pm 0.31$, $6.07 \pm 0.14,6.01 \pm 0.14,5.88 \pm 0.18$ and $5.53 \pm 0.13$ $\log$ CFU g ${ }^{-1}$, respectively.

Although the lowest number of the enterobacteriaceae were observed in the group to which $10 \% \mathrm{PE}$ was applied, the number of enterobacteriaceae and TAMB showed a significant decrease as the extract concentration increased $(\mathrm{P}<0.05)$. Berizi et al (2016) investigated the effect of $1,2,4 \%$ PPE on the quality of trout for 18 months at $-18{ }^{\circ} \mathrm{C}$. At the end of storage, the lowest TAPB counts were detected in trout to which $4 \%$ PPE was applied. At the end of storage, number of TAPB controls and of samples treated with 1,2 and 4\% PPE were determined as 5.14, 4.87, 4.86 and 4.27 $\mathrm{CFU} \mathrm{g}^{-1}$, respectively. In addition, the count of enterobacteriaceae was determined to be lower in the trout samples to which 1, 2 and 4\% PPE was applied in comparison with the control group.
It was reported that the development of TAMB significantly was suppressed in the groups to which $0.1,0.2$ and $0.3 \%$ PPE was added compared to the control group in the study carried out by Özdemir et al (2014). Furthermore, as the concentration of the extract increased, the number of enterobacteriaceae also decreased significantly. The results that we obtained are similar to these studies, and it was seen that the antibacterial quality increases as the extract concentration increases. Contrary to these studies, it was reported that the increase in extract concentration did not increase the antibacterial effect in the study conducted by Basiri et al (2014). These investigators investigated the impact of vacuum packaging and PPE on the quality of pacific white shrimp stored at $+4{ }^{\circ} \mathrm{C}$ for 10 days. TAPB, LAB and enterobacteriaceae numbers were found to be lower than the control group in the PPE supplemented groups.

\section{Conclusions}

The antibacterial effect of PPE on the food pathogens were investigated in this study. It was determined that the PPE have antibacterial effect and that the antibacterial effect significantly increased as the extract concentration increased. It was determined that PE which has antibacterial effects on many food pathogens, primarily on L. monocytogenes, can be used as a natural preservative in seafood products.

\begin{tabular}{|ll|}
\hline Abbreviations and Symbols \\
\hline$P P$ & Pomegranate peel \\
$P P E$ & Pomegranate peel extract \\
$C F U$ & Colony forming unit \\
$T A P B$ & Total aerobic psychrophile bacteria \\
$T A M B$ & Total aerobic mesophile bacteria \\
$M P N$ & Most probable number \\
$T Y M$ & Total yeast-mould \\
$L A B$ & Lactic acid bacteria \\
$T A M B$ & Toplam aerobik mezofilik bakteri \\
$T A P B$ & Toplam aerobik psikrofil bakteri \\
$T M K$ & Toplam maya küf \\
\hline
\end{tabular}




\section{References}

Ahmad I \& Beg A Z (2001). Antimicrobial and phytochemical studies on 45 Indian medicinal plants against multi-drug resistant human pathogens. Journal of Ethnopharmacology 74(2): 113-123

Al-Zoreky N S (2009). Antimicrobial activity of pomegranate (Punica granatum L.) fruit peels. International Journal of Food Microbiology 134(3): 244-248

Balasundram N, Sundram K \& Samman S (2006). Phenolic compounds in plants and agri-industrial by-products: Antioxidant activity, occurrence, and potential uses. Food Chemistry 99(1): 191-203

Basiri S, Shekarforoush S S, Aminlari M, Abhari K \& Berizi E (2014). Influence of combined vacuum packaging and pomegranate peel extract on shelf life and overall quality of pacific white shrimp (Peneous vannamei) during refrigerated storage. Iranian Journal of Veterinary Research 15(1): 23-29

Berizi E, Shekarforoush S S \& Hosseinzadeh S (2016). Effects of methanolic pomegranate peel extract on the chemical, sensory, textural, and microbiological properties of gutted rainbow trout (Oncorhynchus mykiss) during frozen storage. Journal of Food Protection 79(10): 1700-1706

Chan Y C \& Wiedmann M (2009). Physiology and genetics of Listeria monocytogenes survival and growth at cold temperatures. Critical Reviews in Food Science and Nutrition 49(3): 237-253

Dahham S S, Ali M N, Tabassum H \& Khan M (2010). Studies on antibacterial and antifungal activity of pomegranate (Punica granatum L.). AmericanEurasian Journal of Agricultural \& Environmental Sciences 9(3): 273-281

Dursun S \& Erkan N (2009). Yenilebilir protein filmler ve su ürünlerinde kullanım1. Journal of Fisheries Sciences 3(4): 352-373

Emiroğlu Z K, Yemiş G P, Coşkun B K \& Candoğan K (2010). Antimicrobial activity of soy edible films incorporated with thyme and oregano essential oils on fresh ground beef patties. Meat Science 86(2): 283-288

Feresin G E, Tapia A A \& Bustos D A (2000). Antibacterial activity of some medicinal plants from San Juan, Argentina. Fitoterapia 71(4): 429-432

Gullon B, Pintado M E, Pérez-Álvarez J A \& ViudaMartos M (2016). Assessment of polyphenolic profile and antibacterial activity of pomegranate peel (Punica granatum) flour obtained from co-product of juice extraction. Food Control 59: 94-98

Halkman A (2005). Merck Gida Mikrobiyolojisi Uygulamaları. Başak Matbaacılık Ltd. Şti., Ankara

Harrigan W F (1998). Laboratory Methods in Food Microbiology. $3^{\text {rd }}$ ed. San Diego, CA, USA: Academic Press

Hayrapetyan H, Hazeleger W C \& Beumer R R (2012). Inhibition of Listeria monocytogenes by pomegranate (Punica granatum) peel extract in meat paté at different temperatures. Food Control 23(1): 66-72

Jurenka J S (2008). Therapeutic applications of pomegranate (Punica granatum L.): A review. Alternative Medicine Review 13(2): 128-144

Kanatt S R, Chander R \& Sharma A (2010). Antioxidant and antimicrobial activity of pomegranate peel extract improves the shelf life of chicken products. International Journal of Food Science \& Technology 45(2): 216-222

Keyrouz R, Abasq M L, Le Bourvellec C, Blanc N, Audibert L, ArGall E \& Hauchard D (2011). Total phenolic contents, radical scavenging and cyclic voltammetry of seaweeds from Brittany. Food Chemistry 126(3): 831-836

Mathabe M C, Nikolova R V, Lall N \& Nyazema N $\mathrm{Z}$ (2006). Antibacterial activities of medicinal plants used for the treatment of diarrhoea in Limpopo Province, South Africa. Journal of Ethnopharmacology 105(1): 286-293

Melendez P A \& Capriles V A (2006). Antibacterial properties of tropical plants from Puerto Rico. Phytomedicine 13(4): 272-276

Negi P S \& Jayaprakasha G K (2003). Antioxidant and antibacterial activities of Punica granatum peel extracts. Journal of Food Science 68(4): 1473-1477

Owen R J \& Palombo E A (2007). Anti-listerial activity of ethanolic extracts of medicinal plants, Eremophila alternifolia and Eremophila duttonii, in food homogenates and milk. Food Control 18(5): 387-390

Özdemir H, Soyer A, Tağ1 Ş \& Turan M (2014). Nar kabuğu ekstraktının antimikrobiyel ve antioksidan aktivitesinin köfte kalitesine etkisi. G1da-The Journal of Food 39(6): 355-362 
Prashanth D, Asha M K \& Amit A (2001). Antibacterial activity of Punica granatum. Fitoterapia 72(2): 171173

Rawdkuen S, Suthiluk P, Kamhangwong D \& Benjakul A (2012). Antimicrobial activity of some potential active compounds against food spoilage microorganisms. African Journal of Biotechnology 11(74): 13914-13921

Song Y, Liu L, Shen H, You J \& Luo Y (2011). Effect of sodium alginate-based edible coating containing different anti-oxidants on quality and shelf life of refrigerated bream (Megalobrama amblycephala). Food Control 22(3): 608-615

Wu J, Jahncke M L, Eifert J D, O'Keefe S F \& Welbaum G E (2016). Pomegranate peel (Punica granatum L) extract and Chinese gall (Galla chinensis) extract inhibit Vibrio parahaemolyticus and $L$. monocytogenes on cooked shrimp and raw tuna. Food Control 59: 695-699 